\title{
Correction to: Is vitamin C enough? A case report of scurvy in a five-year-old girl and review of the literature
}

Timothy Hahn, Whitney Adams and Keith Williams*

\section{Correction to: BMC Pediatr \\ https://doi.org/10.1186/s12887-019-1437-3}

Following publication of the original article [1], the authors reported that an out-of-date version of Figure 1 had been incorporated in the published article.

Please see here for the updated (correct) version of the figure:

* Correspondence: Feedingprogram@hmc.psu.edu 


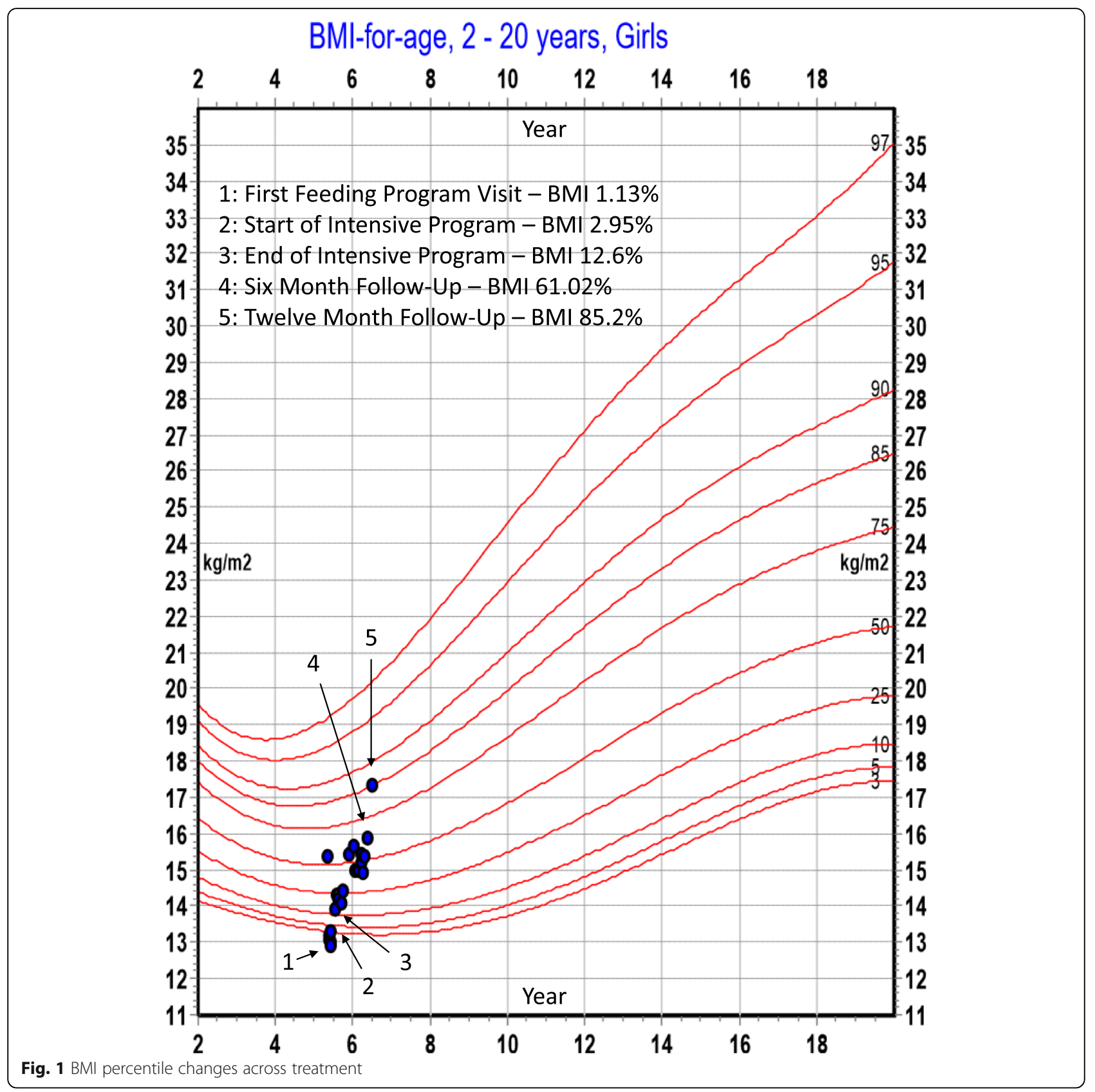

The figure in the original article has been corrected accordingly.

Published online: 16 May 2019

\section{Reference}

1. Hahn T, Adams W, Williams K. Is vitamin C enough? A case report of scurvy

in a five-year-old girl and review of the literature. BMC Pediatr. https://doi.

org/10.1186/s12887-019-1437-3. 